\title{
Research on the Teaching Method of Customer Relationship Management (CRM) in Private Colleges
}

\author{
Weiyi $\mathrm{Li}^{1}$ \\ ${ }^{1}$ Wuhan Technology and Business University, Wuhan China
}

791414950@qq.com

\section{Keywords: CRM; Private College; teaching method}

\begin{abstract}
Now, with the popularity of use of cellphone, increasing amount of college students lose their interests of listening to teacher at class. Especially for some theoretical courses, such as Customer Relationship Management, this situation is even more serious. This article discuss the methods that can be used to make the CRM course become more attractive.
\end{abstract}

\section{Introduction}

At present, most of the private colleges in China are low-end. Even some majors in those colleges, there is no requirement of minimum passing score, tuition becomes the only key to open the gate of those colleges. Therefore, at present, most of the private universities students in China are in poor quality. Those students have terrible study habits also weak self-control ability and it's difficult for them to digest abstract knowledge. Nowadays, high graduation rate becomes the key factor to recruit more high school students for Chinese private colleges. For that reason, it's quite normal for those colleges to lower the standard of examination to make the students get certificate easier, which may reduce their desire to study diligently. So, being absorbed in cellphone, sleeping, reading irrelevant novels becomes a universal outcome. However, once the discipline of class is spoiled, the study atmosphere will become increasingly worse. Currently, almost all the colleges use strict administrative methods to manage classroom, for example, banning the use of cellphone in class, imposing students to sit in front lines or increasing the frequency of checking attendance. But these measures can only relieve pain temporarily, it is impossible to cure the disease permanently. How to pull students back to the lecture? The most effective answer to this question is to improve the way of teaching to motivate students to learn intrinsically.

\section{The Current Situation of Teaching in CRM Course in Private College Class}

The customer relationship management (CRM) course is an elective or compulsory course offered by most private universities. In this course, there is a large amount of knowledge points and concepts for students to understand and handle. Besides that, the knowledge from this field is quite abstract, difficult to understand and far from the students' daily life, such as the concept "the logical model of three layers of relationship marketing". Therefore, these contents are definitely beyond the understanding of many private university students. Most of them are fond of specific and vivid information. Meanwhile, there is barrier for them to understand some abstract and critical knowledge. Plus, limited self-control ability and poor exploring spirit make them turn into cellphone when they meet a new concept beyond their understanding.

Nowadays, the conventional way of teaching is not suitable for the private college students, because this type of students generally are blundering. In their mind, there is a common misunderstanding that all the information from class can be found on cellphone, also they can copy lecturers' electronic coursework to study after class, so the students begin to lose their patience on the lecture. Besides that, in traditional class, the teaching methods are too theoretical to understand. For example, lecturer will firstly claim a new concept, then a general explanation follows, a case study will come at the end. Apparently, it cannot satisfy the needs of private college students. Perhaps, they may lose their attention at the very beginning, if this kind of teaching method applied 
on them. Therefore, for the management courses, such as customer relationship management (CRM), the main task is that how to make theoretical teaching content be more attractive. To realize this, three aspects are extremely important. Firstly, students can understand what they have learned. Secondly, students should feel that the knowledge they learn can help them in their future life. Finally, it will make students realize that what they learn in class cannot be achieved from the mobile phone.

\section{The research on CRM teaching methods in class}

Enhance the understanding of theoretical knowledge points in CRM. A large number of knowledge points in customer relationship management courses are abstract and far away from students' daily life. It is impossible to establish perception to those concepts by forcing the students who have weak abstract thinking ability to memorize those simple explanation. On the contrary, the cognitive efficiency will be brought down if students form an aversion in the process of imparting knowledge. Therefore, teaching on occasion is the most effective way to break the rules of traditional teaching method. What is teaching on occasion? In this method, teacher starts with an actual case and establishes a living scene for the students. Then, a key problem is summarized from the scene. Through the study of cases, the concrete method of solving this practical problem can be found. Finally, a general rules will be concluded.

As an example of customer segmentation from CRM study, most students don't have any concept before they learn the concept of customer segmentation. After learning this chapter content, students need to master three important knowledge points, "What is the customer segmentation", "Why must carry on the customer segmentation", "How to carry on the customer segmentation". In the traditional way of teaching, the definition of customer segmentation will be explained at first and students will be asked to remember it. Finally, those information will be synthesized in a practical case.

However, the method of teaching on occasion is definitely different. In the beginning, the scene will be introduced by case and the main knowledge points will be hided. Take teaching the concept of customer segmentation for example. At first, teacher can use the example of automobile products to let the students to explain an interesting phenomenon, why there are ordinary cars, limousine in the car market. Even one manufacturer will have high-end and low grade brands. Through the import of this familiar scene, it can stimulate students' desire of participation. At the same time, teacher can also ask students some questions they are interested in, such as, what is your dreaming car. After the discussion, the teacher will summarize the core value of the case discussion - the reasons for customer segmentation. When the students know the reasons for this concept, they are most likely to understand the meaning of the concept. At this time, students can be asked to consider the same types of customer segmentation in daily life according to the previous cases. Finally summarize the core concepts. Such teaching method is quite effective to teach some boring theory like the customer relationship management. The method can enhance students' understanding of abstract knowledge and stimulate their interests of learning.

Make students realize the practical value of the knowledge in their future life. Many knowledge points in CRM are corporate customer strategies, which are generally considered by market executives not college undergraduates. Therefore, they will easily lose their motivation to learn the course. So the first thing the teacher needs to know is what does the student care about most in the future? Obviously, concrete life is the most significant issue to concern, such as how to succeed in the workplace, how to have a harmonious relationship. Teacher need to do is find the connections between theoretical knowledge and the practical problems. The teaching goal is to enable students to achieve a better life in the future through learning customer relationship theory.

In the case of customer segmentation, it is the study of how enterprises usually divide the existing customer into four categories according to different contribution of value, platinum customer, gold customer, ordinary customer and no value customer. If the teacher explains this concept from an enterprise management perspective, students are bound to lose their interests. But if teacher can combine this theoretical knowledge with students' daily life, it will be more effective. 
For example, making students imagine their life after five years, when they graduate from college and enter into company. They are rookies in workplace and have moderate income. But at this moment, they are urged to marry by parents. So how to perfectly handle different complex relationship from workplace and family? By learning customer segmentation, students can get some inspirations.

Make students feel the knowledge cannot be obtained from cellphone. The majority of students in private colleges have poor self-control ability and their learning objectives are not clear, so they are easily addicted into play cellphone. There are two reasons why students love to play mobile phones in class. On the one hand, mobile phone is entertaining, which can make them feel relaxed. On the other hand, students have the illusion that the knowledge taught by teachers can be easily obtained through mobile phones. For example, if you enter a keyword in a search engine, the relevant information can be displayed, even more accurate and comprehensive than that taught by the teacher.

However, the biggest drawback of self-learning through mobile phone is that the information obtained by students through mobile phones is fragmented and illogical. Therefore, it is difficult for students to synthesize and summarize the logical relation between knowledge points when studying such information. Moreover, everyone's attention is limited in an age of information explosion. Students will waste a great deal of attentiveness if they focus on much little valued information from mobile phone. It will make them cannot think deeply when they face important knowledge, so their learning efficiency will be reduced.

Therefore, the teacher should have a very clear logical architecture of teaching system when they teach customer relationship management (CRM) course. At the beginning of the learning process, students will be definitely told that to learn to learn this course is to solve the problems closely related to their own life.

\section{Summary}

At present, with the increasing popularity of cellphone among college students, college students are more likely to be addicted into cellphone without listening to teacher in class. It is even much worse for the private students who have low self-control ability. Only if the teachers reform their teaching methods through the research on learning theory of customer relationship management (CRM) above, the students will be dragged back to class. Also, the boring theory classes will also become lively and interesting.

\section{References}

[1] Minghui Ouyang: Research on the Current Situation and Countermeasures of China's Cross-Border E-Commerce Logistics[J], Logistics Engineering and Management, 2016, 38(06):104-106.

[2]Yan Zheng. Manager Competency [M]. Beijing: China Machine Press, 2014.16-17

[3] Jiangqiao Mei: Research on Demand Characteristics of Cross-Border E-Commerce Talents[J], Management Observer, 2014(31):119-120.

[4]Fei Donghua. Employee Computer [M].Beijing: China Economic Press, 2014.18-19

[5]Gaziel Haim Principal of Performance Assessment case study, Giusepp Omega.Vol.94.pp.95-103,2013

[5]Cao Jingjing. Building of Assessment Criterion System for International Development Level of the Professional Market [J]. Statistics and Decision, 2011 (10): 73-75

[6]Xiao Mingzheng. Personnel Quality Test. Higher Education Press, 2015.35-38

[7]Richard S Williams. Performance Mangement. London: International Thomson Business Press.2010:104

[8]Qiuwen Zhang, Ming Zhong. Using Multi-level Fuzzy Comprehensive Evaluation to Assess Reservoir Induced 
[9] Xiaolan Zhuang: Demand Analysis and Training Strategies for Core Talents of Cross Border E-Commerce[J], Management Observer, 2015(17):178-180.

[10] Yulan Zhan: Analysis of the Core Positions and Skills Requirements of Cross Border E-Commerce Talents and Countermeasures -- Based on the Perspective of International Trade Major of Higher Vocational Education[J], China Market, 2018(02):148-149. 